\title{
Effects of Velocity and Weight Support on Ground Reaction Forces and Metabolic Power During Running
}

\author{
Alena M. Grabowski and Rodger Kram \\ University of Colorado
}

The biomechanical and metabolic demands of human running are distinctly affected by velocity and body weight. As runners increase velocity, ground reaction forces (GRF) increase, which may increase the risk of an overuse injury, and more metabolic power is required to produce greater rates of muscular force generation. Running with weight support attenuates GRFs, but demands less metabolic power than normal weight running. We used a recently developed device (G-trainer) that uses positive air pressure around the lower body to support body weight during treadmill running. Our scientific goal was to quantify the separate and combined effects of running velocity and weight support on GRFs and metabolic power. After obtaining this basic data set, we identified velocity and weight support combinations that resulted in different peak GRFs, yet demanded the same metabolic power. Ideal combinations of velocity and weight could potentially reduce biomechanical risks by attenuating peak GRFs while maintaining aerobic and neuromuscular benefits. Indeed, we found many combinations that decreased peak vertical GRFs yet demanded the same metabolic power as running slower at normal weight. This approach of manipulating velocity and weight during running may prove effective as a training and/or rehabilitation strategy.

Keywords: biomechanics, energetics, lower-body positive pressure

Running velocity and weight support each affect the biomechanics and metabolic demands of human running.

The authors are with the Department of Integrative Physiology, University of Colorado, Boulder, CO.
Previous studies have either determined the effects of running velocity at normal body weight (e.g., Daniels \& Gilbert, 1979; Hamill et al., 1983; Munro et al., 1987; Nilsson \& Thorstensson, 1989) or have determined the effects of body weight support at constant running velocities (Chang et al., 2000; Farley \& McMahon, 1992; He et al., 1991; Teunissen et al., 2007). However, the combined effects of running velocity and weight support have not been systematically investigated.

At faster running velocities, peak vertical and horizontal ground reaction forces (GRFs) increase, contact times decrease, and duty factors decrease (Hamill et al., 1983; Munro et al., 1987; Nilsson \& Thorstensson, 1989). The increased magnitude of the vertical impact peak GRF and rate of vertical impact loading have been associated with an increased risk of overuse running injury (Ferber et al., 2002; Gerlach et al., 2005; Hreljac et al., 2000; Zifchock et al., 2006). Evidence also suggests that greater vertical active peak GRFs play a significant role in the risk of overuse running injuries (Grimston et al., 1993; Hreljac, 2004; Messier et al., 1991). Impact peaks typically occur within the first $10 \%$ of the stance period; they are passive vertical forces resulting from the collision of the heel and lower leg mass with the ground following heel strike (Liu \& Nigg, 2000). Impact peaks typically reach magnitudes of 1.5 times body weight at slow velocities $(2 \mathrm{~m} / \mathrm{s}$ ) and increase to 3.0 times body weight at faster velocities ( $7 \mathrm{~m} / \mathrm{s})$ (Cavanagh \& Lafortune, 1980; Hamill \& Knutzen, 1995; Munro et al., 1987; Nilsson \& Thorstensson, 1989). Active peak GRFs reflect the generation of force by the muscles and occur when the center of mass is at its lowest point during midstance. Active peaks typically reach magnitudes of 2.5-2.8 times body weight and also increase with velocity (Cavanagh \& Lafortune, 1980; Hamill \& Knutzen, 1995; Munro et al., 1987; Nilsson et al., 1985). Runners that initially 
strike the ground with their heel produce a characteristic vertical GRF pattern with two peaks: an initial impact peak followed by an active peak (Cavanagh \& LaFortune, 1980). Runners that initially strike the ground with their mid- or forefoot produce a GRF pattern with only one characteristic peak, the active peak.

When body weight is supported during running, peak GRFs are attenuated and the metabolic power demand is less than normal weight running. Previous studies have shown that vertical impact peak GRFs, vertical active peak GRFs, vertical impulses, and horizontal peak GRFs decrease linearly with body weight support (Chang et al., 2000; Teunissen et al., 2007). Therefore, weightsupported running could be used as a training tool to reduce the risk of overuse injury or as a rehabilitation tool to speed recovery after an injury or surgery. However, because metabolic power decreases linearly and in less than direct proportion to weight support (Farley \& McMahon, 1992; Teunissen et al., 2007), weight supported running may not accrue the same cardiovascular benefits as normal weight running.

As human runners increase velocity, their metabolic energy requirements increase proportionately (Costill \& Fox, 1969; Daniels \& Gilbert, 1979). Athletes and coaches have used the increased metabolic power required to run at fast velocities to enhance training and performance from the acquired improvements in cardiovascular function (Costill, 1979; Daniels, 2005). Fast velocity running is also thought to enhance neuromuscular function (Costill, 1979; Daniels, 2005) and involve greater rates of muscular force generation (Roberts et al., 1998; Weyand et al., 2000). However, running at fast velocities cannot be sustained and likely increases the risk of overuse injury due to greater peak GRFs.

In the current study, our basic scientific goal was to quantify the separate and combined effects of running velocity and body weight support on peak vertical GRFs and metabolic power demand. Based on results from previous studies, we expected that peak vertical GRFs would increase with velocity, but would decrease with weight support (Chang et al., 2000; Teunissen et al., 2007). We also expected that metabolic power demand would increase linearly with velocity given that this relationship has been demonstrated many times (e.g., Brooks et al., 2004; Costill \& Fox, 1969). Teunissen et al. 2007 concluded that generating force to support body weight is the primary determinant of the metabolic cost of level running, comprising approximately $74 \%$ of the net cost. The remaining percentage of net cost is presumably due to the tasks of braking/propelling the center of mass in the fore-aft direction and swinging the legs forward. Accordingly, we expected that metabolic rate would decrease linearly and in less than direct proportion with weight support (i.e., at $50 \%$ body weight, metabolic power would decrease by less than $50 \%$ ).

Our practical goal was to identify velocity and weight support combinations that differed in peak vertical GRFs, but demanded equal metabolic power. We predicted that, compared with running slower at normal weight, running fast with weight support would decrease peak vertical GRFs, but demand the same metabolic power. To support body weight, we used a novel lower-body positive air pressure chamber (G-trainer) that contained a force-measuring treadmill.

\section{Methods}

\section{Subjects}

Ten healthy recreational runners volunteered ( 7 male, 3 female; mean body mass of $64.4 \mathrm{~kg}, S D 7.4)$. All subjects were experienced treadmill runners. Before participating, subjects gave informed written consent according to the University of Colorado Human Research Committee approved protocol. Subjects ran on a force-measuring treadmill (FTM) at normal weight and with weight support. We measured ground reaction forces (GRFs) along with rates of oxygen consumption and carbon dioxide production.

\section{Protocol}

Each subject completed 13 trials during two experimental sessions: eight trials on the first day and five trials on the second day. Trials were $7 \mathrm{~min}$ long with at least $3 \mathrm{~min}$ rest given between. Subjects began each session with a standing trial at 1.0 body weight (BW). After the standing trial on the first day, subjects completed a $3.0 \mathrm{~m} / \mathrm{s}$ running trial at $1.0 \mathrm{BW}$ and ended the session with the same $3.0 \mathrm{~m} / \mathrm{s}$ running trial at $1.0 \mathrm{BW}$. The comparison of these two trials allowed us to assess any possible effects of fatigue. We randomly assigned the order of the other trials. Subjects ran $3.0 \mathrm{~m} / \mathrm{s}$ at $0.75,0.50$, and $0.25 \mathrm{BW}$; $4.0 \mathrm{~m} / \mathrm{s}$ at $1.0,0.75,0.50$; and $0.25 \mathrm{BW}$, and $5.0 \mathrm{~m} / \mathrm{s}$ at 0.50 and $0.25 \mathrm{BW}$.

\section{Body Weight Support}

We used a device called the G-trainer, created by Alter-G, Inc. (Menlo Park, CA) to support body weight (Figure $1)$. This commercial device is based on the research device designed by Whalen et al. (1994). The G-trainer is an enclosed treadmill body-weight-support system that uses a small increase in air pressure around the user's lower body to create a lifting force approximately at the person's center of mass. The airtight chamber of the G-trainer contained an aperture that surrounded the subject's waist. Each subject wore a pair of flexible neoprene shorts that included a kayak-style spray skirt and zipper that attached to the aperture. This interface created a substantially airtight seal near the subject's waist. An air pressure in the chamber of less than $10.3 \mathrm{kPa}$, or 1.5 psi, can support up to $80 \%$ of body weight. We applied the appropriate lifting force to each subject by adjusting the air pressure inside the chamber. The applied upward force was nearly constant during the weight support trials. 
For example, pressure fluctuated within a range of $1 \%$, $2 \%$, and $7 \%$ of the mean pressure that was set for each $0.25,0.50$, and $0.75 \mathrm{BW}$ condition, respectively. The G-trainer supported body weight, and stabilized subjects in the anterior/posterior and lateral directions, yet did not affect the swinging limbs.

\section{Force-Measuring Treadmill}

We used a custom-made motorized force treadmill (Kram et al., 1998) that measured vertical and horizontal GRFs for all trials. We collected $15 \mathrm{~s}$ of data at 1000 $\mathrm{Hz}$ between Minutes 4 and 5 of each 7-min trial. To process our GRF data, we used a fast Fourier analysis to determine the specific frequency range of the vibration noise coming from the treadmill motor and used this frequency range for a band-stop filter. Using a custom Matlab program (Natick, MA), we filtered the raw data with a 4th-order Butterworth band-stop digital filter with a range of $26.5-28 \mathrm{~Hz}$, followed by a 4th-order recursive, zero phase-shift Butterworth low-pass filter with a cutoff frequency of $100 \mathrm{~Hz}$ to filter the high-frequency noise. Using the filtered data, we determined contact times, stride frequencies, average body weight, peak vertical GRFs, vertical loading rates, and horizontal impulses for 10 strides per trial. Vertical loading rate was defined as the average slope of the vertical GRF vs. time curve between heel-strike and peak impact GRF.

\section{Metabolic Rate}

We measured and averaged the rates of oxygen consumption and carbon dioxide production during Minutes 4 to 6 of each 7-min trial using an open-circuit respirometry system (Physio-Dyne Instrument, Quogue, NY). Then we calculated gross metabolic power in W/kg of normal

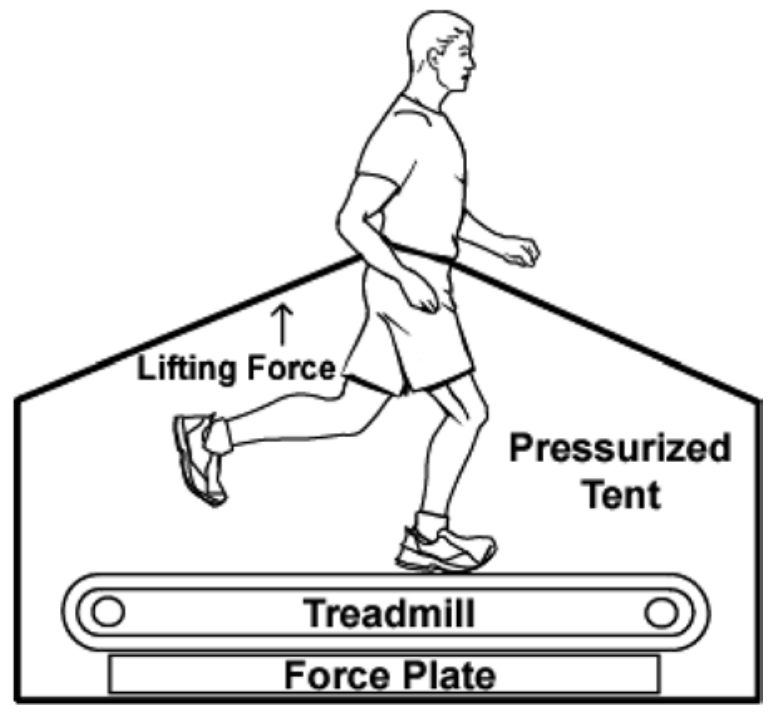

Figure 1 - Lower-body positive pressure apparatus (G-trainer). body mass (Brockway, 1987). We present gross metabolic rate data rather than net metabolic rate because training objectives are often expressed as percentage of maximal metabolic rate. Respiratory exchange ratios were less than 1.0 for all subjects and all trials, which indicated that metabolic energy was supplied primarily by oxidative metabolism.

\section{Statistics}

We used repeated-measures ANOVAs with Tukey HSD follow-up tests when warranted to compare peak vertical GRFs and loading rates, and gross metabolic power $(p<$ $.05)$. We used linear least-squares regression equations to separately compare velocity and weight support to peak vertical GRFs, vertical loading rates, and gross metabolic power. We used multiple linear regressions to determine the combined effects of velocity and weight support on vertical impact peak GRF, vertical active peak GRF, vertical loading rate, and gross metabolic power. The multiple linear regressions for impact peak, vertical loading rate, and gross metabolic power did not include 1.0 BW trials. Our rationale for this exclusion is addressed in the discussion section. Seven of ten subjects were heel strikers; therefore, statistics performed on impact peak and vertical loading rate had $n=7$.

\section{Results}

At all levels of weight support, vertical impact peak GRF, active peak GRF, and loading rate increased linearly with velocity (Figure 2), similar to previous results for running at normal body weight (Munro et al., 1987; Nilsson \& Thorstensson, 1989). Vertical impact peak GRF, active peak GRF, and loading rate decreased linearly with weight support at all velocities (Figure 3 ). We measured and averaged impact peaks and vertical loading rates on the seven subjects who were heel strikers, and active peaks on all 10 subjects. Subjects were designated as a heel striker if their vertical GRF trace had an impact peak. Typical vertical GRF patterns for a heel striker during all velocity and weight support conditions are shown in Figure 4.

Both velocity and weight support were significant predictors of vertical impact peak (IP), active peak (AP), and loading rate (VLR). The multiple regression equations for these variables were as follows: $\mathrm{IP}=1.80 \mathrm{BW}+$ $0.24 \mathrm{v}-0.35\left(R^{2}=0.58\right) ; \mathrm{AP}=2.00 \mathrm{BW}+0.17 \mathrm{v}-0.06\left(R^{2}\right.$ $=0.86) ; \mathrm{VLR}=66.12 \mathrm{BW}+20.35 \mathrm{v}-55.53\left(R^{2}=0.51\right)$, where IP and AP are in units of body weights (i.e., 1.0 = normal body weight), VLR is in units of body weights per second, $\mathrm{v}$ is in units of meters per second, and BW is a decimal fraction of body weight (Figure 5). A decrease in either velocity or weight attenuated peak GRFs and loading rates. For example, a $1 \mathrm{~m} / \mathrm{s}$ decrease in velocity from $4 \mathrm{~m} / \mathrm{s}$ to $3 \mathrm{~m} / \mathrm{s}$ at $0.75 \mathrm{BW}$ would attenuate IP, AP, and VLR by $0.24 \mathrm{BW}, 0.16 \mathrm{BW}$, and $20.35 \mathrm{BW} / \mathrm{s}$, respectively. Thus, based on the multiple regression equations 


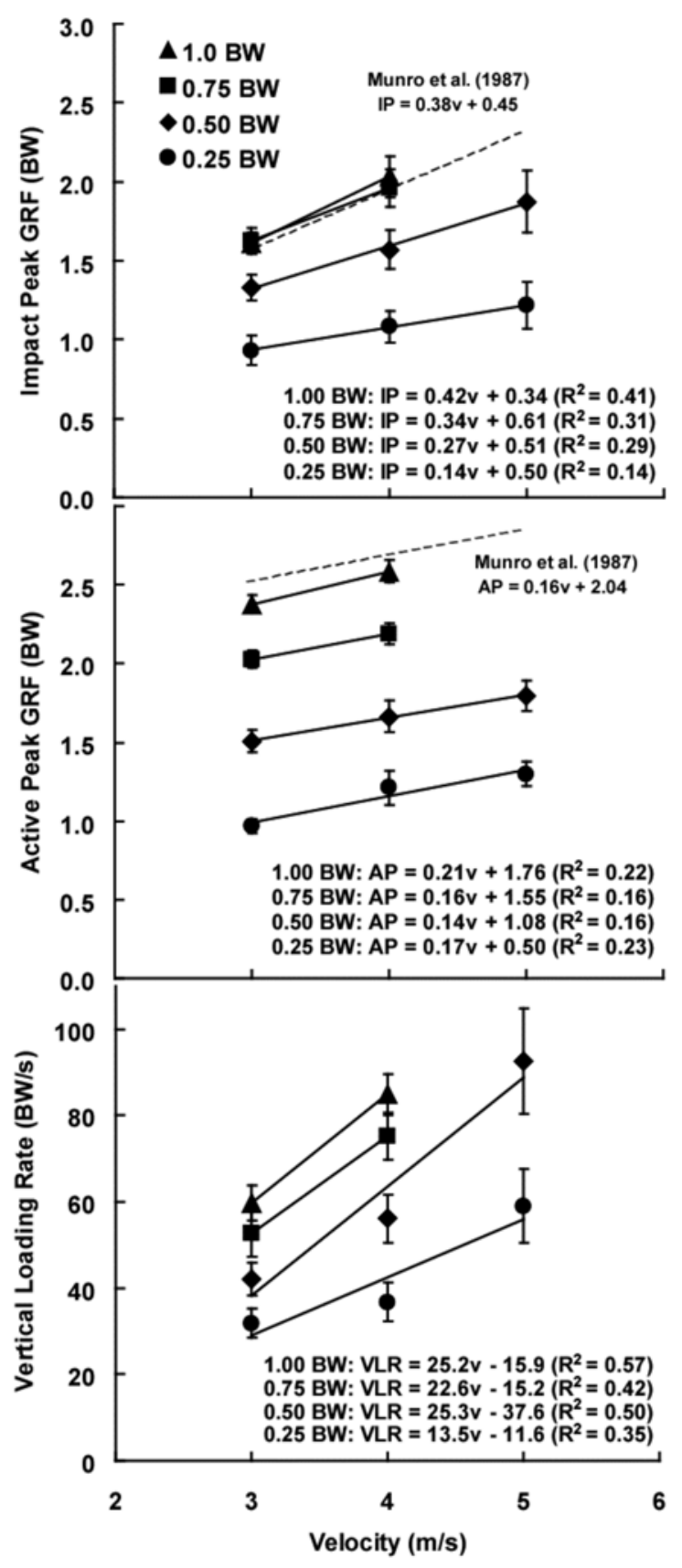

Figure 2 - Impact peak $(n=7)$, active peak $(n=10)$, and vertical loading rate $(n=7)$ at 3,4 , and $5 \mathrm{~m} / \mathrm{s}$ at normal weight and with weight support. Impact and active peak GRFs at 1.0 $\mathrm{BW}$ are compared with data represented with a dashed line from Munro et al. (1987). Solid symbols are subject means, error bars are s.e.m., and solid lines are linear least-squares regressions from individual subject data.

for velocity and weight support, peak GRFs and loading rate would be attenuated by the same amounts as this 1 $\mathrm{m} / \mathrm{s}$ example if BW was changed from $4 \mathrm{~m} / \mathrm{s}$ at $0.75 \mathrm{BW}$ to $4 \mathrm{~m} / \mathrm{s}$ at $0.62 \mathrm{BW}$ for IP, $0.67 \mathrm{BW}$ for $\mathrm{AP}$, and 0.45

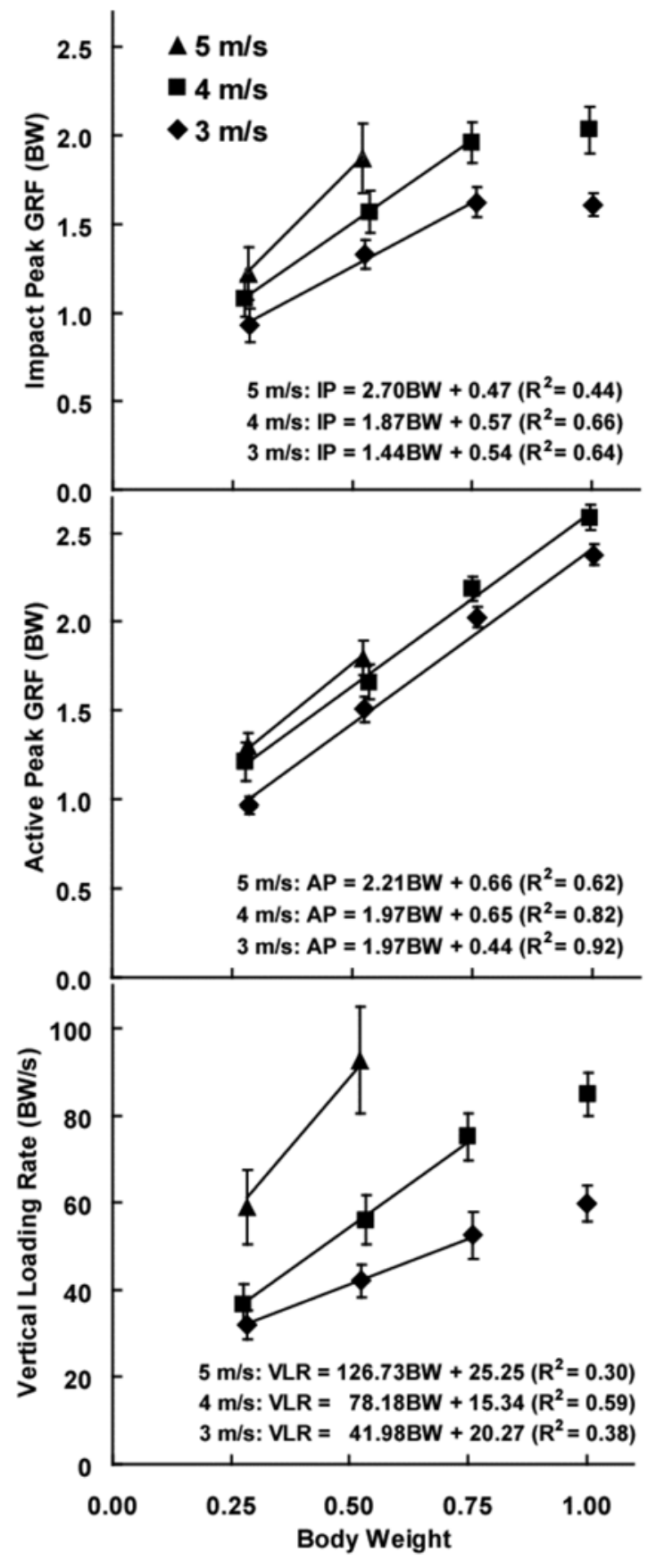

Figure 3 - Impact peak $(n=7)$, active peak $(n=10)$, and vertical loading rate $(n=7)$ at normal weight and with weight support while running 3,4 , and $5 \mathrm{~m} / \mathrm{s}$. Solid symbols are subject means, error bars are s.e.m., and solid lines are linear leastsquares regressions from individual subject data.

BW for VLR (a decrease of 0.13 BW, 0.08 BW, and 0.30 $\mathrm{BW}$, respectively).

Gross metabolic power increased linearly with velocity at 1.0 BW (Figure 6) and was comparable to 


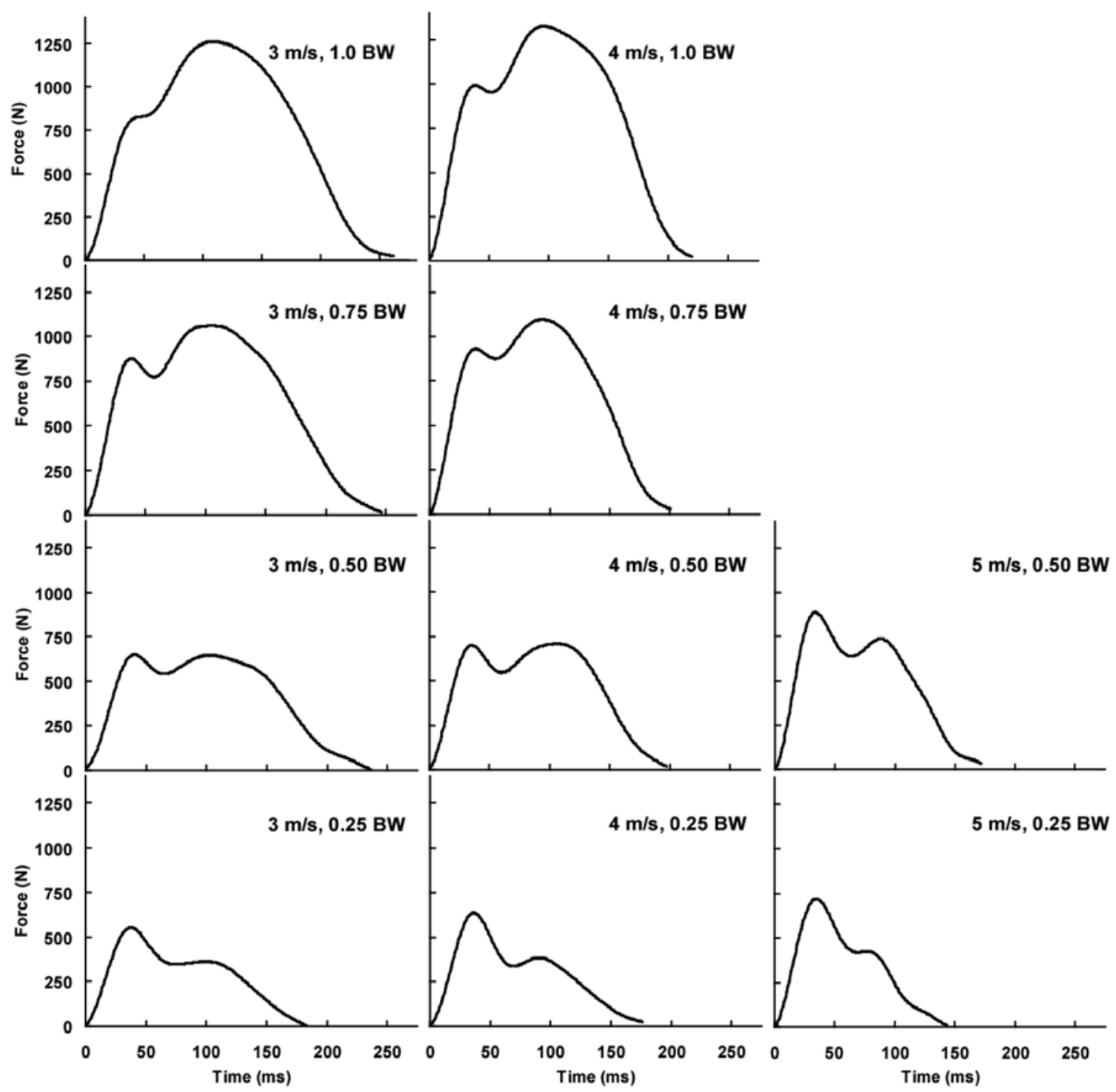

Figure 4 - Vertical GRF traces versus time from a representative heel striker (subject weight $=568 \mathrm{~N}$ ) for each condition. Vertical GRF is measured in newtons.

other running economy values reported in the literature (Brooks et al., 2004; Conley \& Krahenbuhl, 1980; Daniels \& Gilbert, 1979). At all levels of weight support, gross metabolic power increased linearly with velocity (Figure 6). Similar to previous studies (Farley \& McMahon, 1992; Teunissen et al., 2007), gross metabolic power decreased linearly and in slightly less than direct proportion with weight support at all velocities (Figure 7).

Both velocity $(\mathrm{V})$ and weight $(\mathrm{BW})$ were significant predictors of gross metabolic power. The multiple regression equation describing gross metabolic power (GMP) as a function of velocity and weight support was GMP $=6.11 \mathrm{BW}+2.29 \mathrm{v}-2.65\left(R^{2}=0.49\right)$, where GMP is in units of watts per kilogram, $v$ is in units of meters per second, and BW is a decimal fraction of body weight (Figure 8). A decrease in either velocity or weight demanded less metabolic power. For example, a $1 \mathrm{~m} / \mathrm{s}$ decrease in velocity from $4 \mathrm{~m} / \mathrm{s}$ to $3 \mathrm{~m} / \mathrm{s}$ at $0.75 \mathrm{BW}$ would decrease metabolic power by $2.29 \mathrm{~W} / \mathrm{kg}$. Thus, based on the multiple regression equations for velocity and weight support, metabolic rate would decrease by the same amount as this $1 \mathrm{~m} / \mathrm{s}$ example if $\mathrm{BW}$ was changed from $4 \mathrm{~m} / \mathrm{s}$ at $0.75 \mathrm{BW}$ to $4 \mathrm{~m} / \mathrm{s}$ at $0.37 \mathrm{BW}$ (a decrease of $0.38 \mathrm{BW}$ ).

Subjects did not exhibit any significant differences in impact peak $(p=.77)$, active peak $(p=.99)$, vertical loading rate $(p=.38)$, or metabolic power $(p=.82)$, between the initial and final $3 \mathrm{~m} / \mathrm{s}$ at $1.0 \mathrm{BW}$ trials from the first day, thus indicating that fatigue did not influence our results and that runners' kinetics and kinematics 


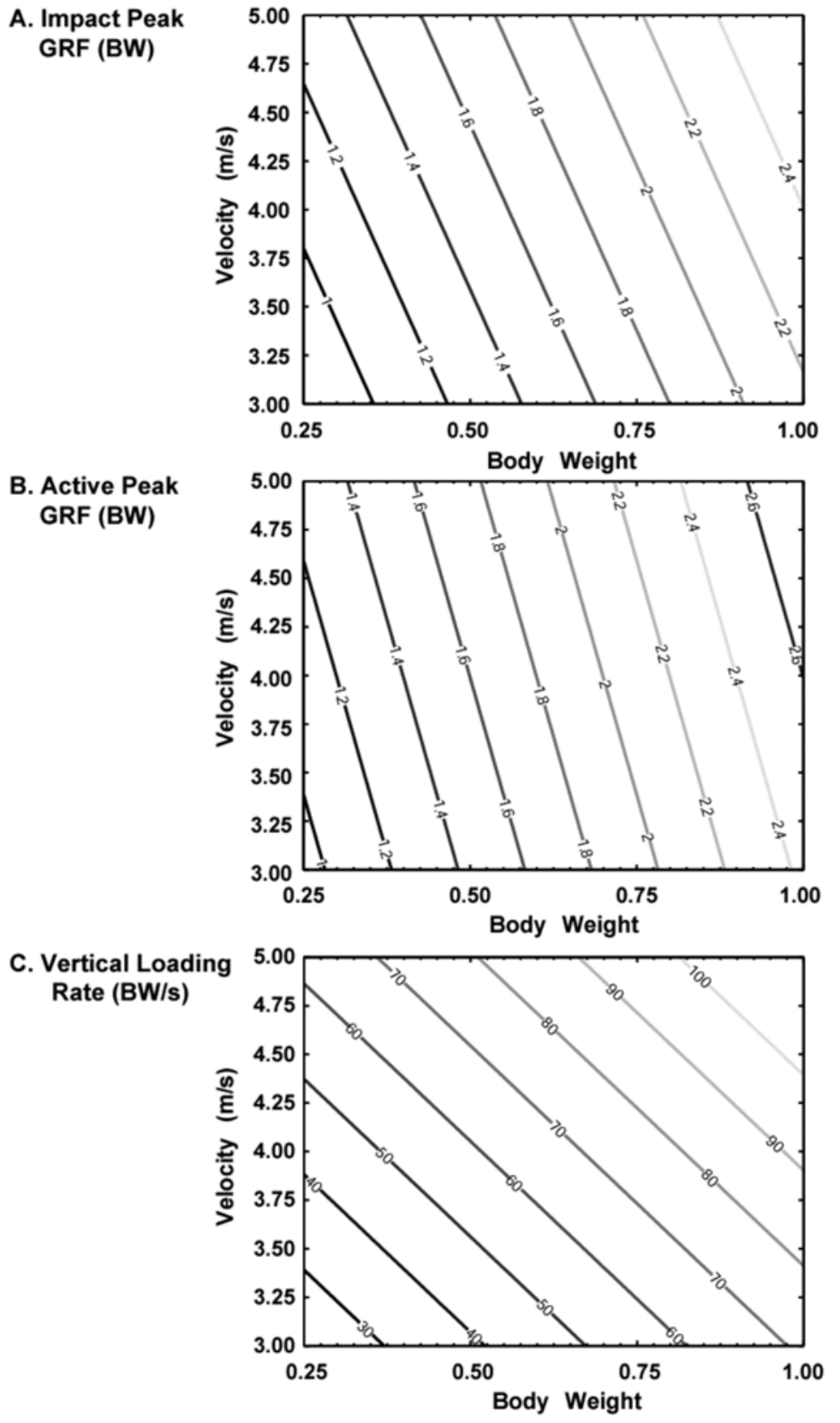

Figure 5 - A. Contour plot of impact peak (IP); B. contour plot of active peak (AP); and C. contour plot of vertical loading rate (VLR) over a range of velocities and weight support based on the multiple regression equations, $\mathrm{IP}=1.80 \mathrm{BW}+0.24 \mathrm{v}-0.35\left(R^{2}=\right.$ $0.58) ; \mathrm{AP}=2.00 \mathrm{BW}+0.17 \mathrm{v}-0.06\left(R^{2}=0.86\right) ; \mathrm{VLR}=66.12 \mathrm{BW}+20.35 \mathrm{v}-55.53\left(R^{2}=0.51\right)$. $\mathrm{BW}$ is a decimal fraction of body weight and $\mathrm{v}$ is velocity in $\mathrm{m} / \mathrm{s}$. The multiple regression equations and plots are extrapolated from $0.75 \mathrm{BW}$ to $1.0 \mathrm{BW}$.

generally returned to normal for the final trial at 1.0 BW (Table 1). However, after having run with weight support, all subjects reported a profound yet transient feeling of "heavy legs" that may have resulted in longer contact times during the final $3 \mathrm{~m} / \mathrm{s}$ normal weight trial (Table 2).

Using our data and regression equations, we found velocity and weight support combinations that resulted in different impact peaks, active peaks, and vertical loading rates, but required the same metabolic power (Figures $3,5,7,8)$. Running at faster velocities with weight support does not change impact peaks substantially, but greatly reduces active peak GRFs and increases vertical loading rates, yet requires the same metabolic power as running at slower velocities with normal weight. For example, running $3 \mathrm{~m} / \mathrm{s}$ at $1.0 \mathrm{BW}$ demands $11.68 \mathrm{~W} /$ 


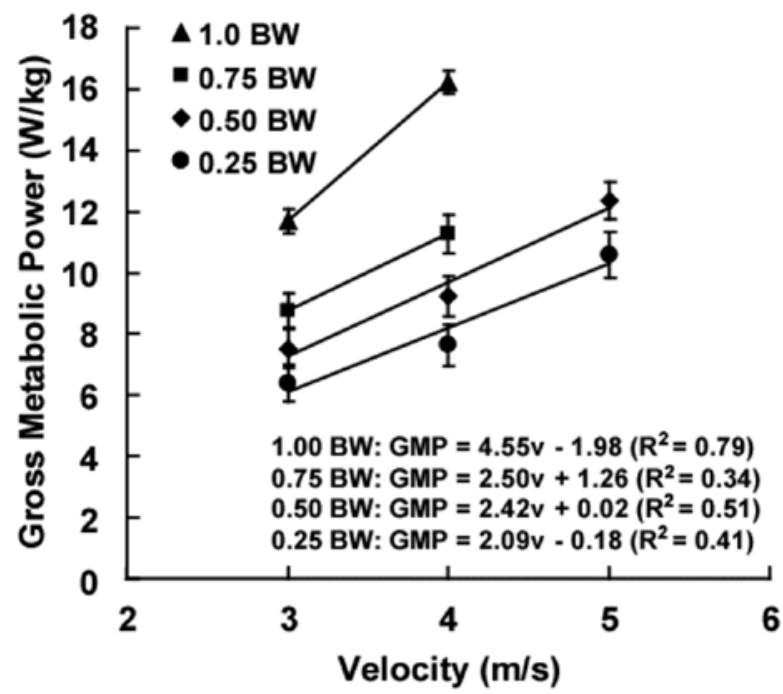

Figure 6 - Gross metabolic power for 3,4 , and $5 \mathrm{~m} / \mathrm{s}$ at normal weight and with weight support. Solid symbols are means for 10 subjects, error bars are s.e.m., and solid lines are linear least-squares regressions from individual subject data. Please note that the horizontal axis begins at $2 \mathrm{~m} / \mathrm{s}$, not zero.

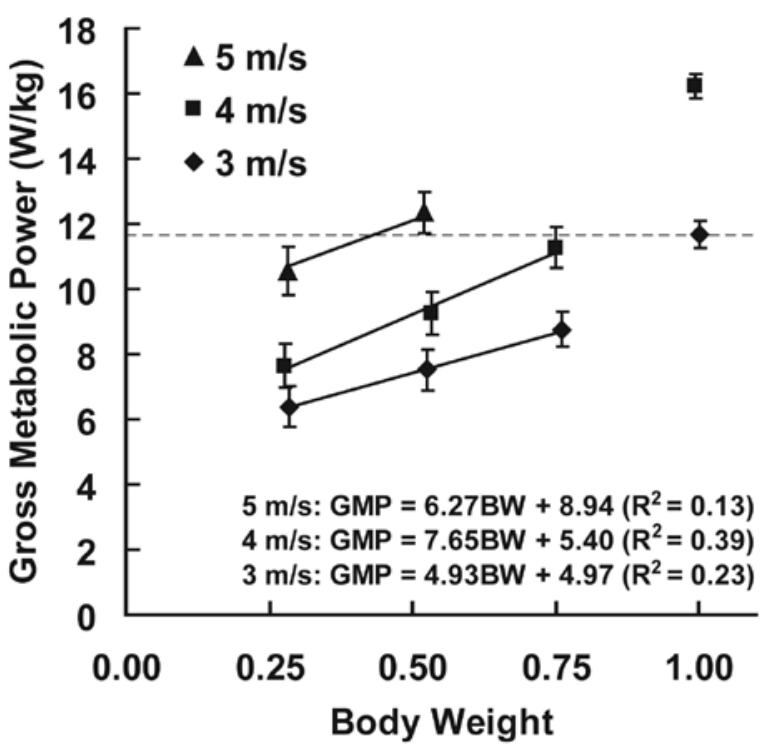

Figure 7-Gross metabolic power at normal weight and with weight support while running 3,4 , and $5 \mathrm{~m} / \mathrm{s}$. Solid symbols are means for 10 subjects, error bars are s.e.m., and solid lines are linear least-squares regressions from individual subject data. Dashed horizontal line indicates gross metabolic power demand at $3 \mathrm{~m} / \mathrm{s}$ and $1.0 \mathrm{BW}$. This line provides a visual reference to compare other combinations of velocity and weight support that have the same metabolic demand.

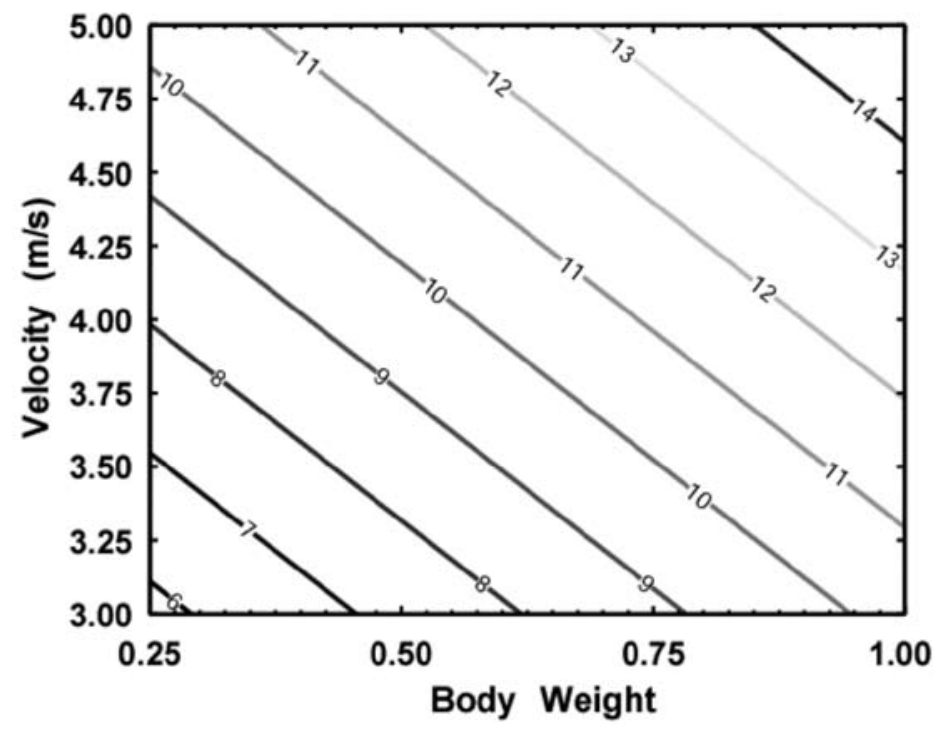

Figure 8 - Contour plot of gross metabolic power (GMP) over a range of velocities and weight support based on the multiple regression equation, $\mathrm{GMP}=6.11 \mathrm{BW}+2.29 \mathrm{v}-2.65\left(R^{2}=0.49\right)$. BW is a decimal fraction of body weight and $\mathrm{v}$ is velocity in $\mathrm{m} / \mathrm{s}$. The multiple regression equation and plot are extrapolated from $0.75 \mathrm{BW}$ to $1.0 \mathrm{BW}$.

$\mathrm{kg}$ of metabolic power (Table 1). Running $4 \mathrm{~m} / \mathrm{s}$ at 0.82 BW and $5 \mathrm{~m} / \mathrm{s}$ at $0.43 \mathrm{BW}$ would both demand the same gross metabolic power of $11.68 \mathrm{~W} / \mathrm{kg}$ based on the linear regression equations for each velocity (Figure 7). Vertical impact peak GRF, active peak GRF, and loading rate while running $3 \mathrm{~m} / \mathrm{s}$ at $1.0 \mathrm{BW}$ were $1.61 \mathrm{BW}, 2.38$ $\mathrm{BW}$, and $59.71 \mathrm{BW} / \mathrm{s}$, respectively (Table 1, Figure 3). When running $4 \mathrm{~m} / \mathrm{s}$ at $0.82 \mathrm{BW}$, we predict that impact peak would increase to $2.10 \mathrm{BW}$, active peak would decrease to $2.27 \mathrm{BW}$, and loading rate would increase to 
Table 1 Means ( \pm SEM); Body Weight (BW)

\begin{tabular}{lccccc}
\hline Average BW & Velocity, $\mathbf{m} / \mathbf{s}$ & Impact peak, BW & Active peak, BW & Vertical loading rate, BW/s & $\begin{array}{c}\text { Gross metabolic } \\
\text { power, W/kg }\end{array}$ \\
\hline $1.00(0.00)$ & 3 & $1.61(0.07)$ & $2.38(0.06)$ & $59.71(4.15)$ & $11.68(0.41)$ \\
$0.76(0.01)$ & 3 & $1.62(0.08)$ & $2.03(0.05)^{\mathrm{a}}$ & $52.59(5.44)$ & $8.77(0.54)^{\mathrm{a}}$ \\
$0.53(0.01)$ & 3 & $1.33(0.08)^{\mathrm{a}}$ & $1.51(0.07)^{\mathrm{a}}$ & $42.07(3.75)^{\mathrm{W}}$ & $7.51(0.63)^{\mathrm{a}}$ \\
$0.28(0.01)$ & 3 & $0.93(0.09)^{\mathrm{a}}$ & $0.97(0.04)^{\mathrm{a}}$ & $31.89(3.33)^{\mathrm{a}}$ & $6.39(0.62)^{\mathrm{a}}$ \\
$0.99(0.00)$ & 4 & $2.03(0.13)^{\mathrm{b}}$ & $2.59(0.07)^{\mathrm{b}}$ & $84.91(4.83)^{\mathrm{b}}$ & $16.24(0.38)^{\mathrm{b}}$ \\
$0.75(0.01)$ & 4 & $1.96(0.12)^{\mathrm{b}}$ & $2.19(0.07)^{\mathrm{ab}}$ & $75.17(5.45)^{\mathrm{ab}}$ & $11.27(0.62)^{\mathrm{ab}}$ \\
$0.54(0.02)$ & 4 & $1.57(0.12)^{\mathrm{ab}}$ & $1.66(0.10)^{\mathrm{ab}}$ & $56.10(5.56)^{\mathrm{ab}}$ & $9.24(0.65)^{\mathrm{ab}}$ \\
$0.28(0.01)$ & 4 & $1.08(0.10)^{\mathrm{ab}}$ & $1.21(0.11)^{\mathrm{a}}$ & $36.76(4.51)^{\mathrm{a}}$ & $7.64(0.67)^{\mathrm{ab}}$ \\
$0.52(0.02)$ & 5 & $1.87(0.20)^{\mathrm{b}}$ & $1.80(0.10)^{\mathrm{b}}$ & $92.68(12.27)^{\mathrm{b}}$ & $12.35(0.62)^{\mathrm{b}}$ \\
$0.28(0.01)$ & 5 & $1.22(0.15)^{\mathrm{a}}$ & $1.30(0.08)^{\mathrm{a}}$ & $58.98(8.56)^{\mathrm{ab}}$ & $10.58(0.74)^{\mathrm{ab}}$ \\
$0.99(0.00)$ & 3 & $1.62(0.09)$ & $2.38(0.05)$ & $63.71(5.55)$ & $11.79(0.47)$ \\
\hline
\end{tabular}

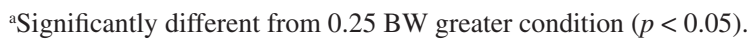

${ }^{\mathrm{b}}$ Significantly different from $1 \mathrm{~m} / \mathrm{s}$ slower condition $(p<0.05)$.

Table 2 Means ( \pm SEM); Body Weight (BW)

\begin{tabular}{lccc}
\hline $\begin{array}{l}\text { Average } \\
\text { BW }\end{array}$ & $\begin{array}{c}\text { Velocity, } \\
\mathbf{m} / \mathbf{s}\end{array}$ & $\begin{array}{c}\text { Contact time, } \\
\mathbf{s}\end{array}$ & $\begin{array}{c}\text { Stride frequency, } \\
\mathbf{H z}\end{array}$ \\
\hline $1.00(0.00)$ & 3 & $0.20(0.01)$ & $1.49(0.05)$ \\
$0.76(0.01)$ & 3 & $0.22(0.01)^{\mathrm{a}}$ & $1.41(0.05)^{\mathrm{a}}$ \\
$0.53(0.01)$ & 3 & $0.24(0.01)^{\mathrm{a}}$ & $1.37(0.03)^{\mathrm{a}}$ \\
$0.28(0.01)$ & 3 & $0.25(0.01)^{\mathrm{a}}$ & $1.32(0.03)^{\mathrm{a}}$ \\
$0.99(0.00)$ & 4 & $0.17(0.00)^{\mathrm{b}}$ & $1.57(0.06)^{\mathrm{b}}$ \\
$0.75(0.01)$ & 4 & $0.19(0.01)^{\mathrm{ab}}$ & $1.48(0.04)^{\mathrm{ab}}$ \\
$0.54(0.02)$ & 4 & $0.20(0.00)^{\mathrm{ab}}$ & $1.44(0.04)^{\mathrm{ab}}$ \\
$0.28(0.01)$ & 4 & $0.22(0.00)^{\mathrm{ab}}$ & $1.39(0.04)^{\mathrm{b}}$ \\
$0.52(0.02)$ & 5 & $0.14(0.00)^{\mathrm{b}}$ & $1.53(0.06)^{\mathrm{b}}$ \\
$0.28(0.01)$ & 5 & $0.16(0.00)^{\mathrm{ab}}$ & $1.48(0.04)^{\mathrm{ab}}$ \\
$0.99(0.00)$ & 3 & $0.25(0.01)$ & $1.49(0.04)$ \\
\hline
\end{tabular}

${ }^{a}$ Significantly different from $0.25 \mathrm{BW}$ greater condition $(p<0.05)$. ${ }^{\mathrm{b}}$ Significantly different from $1 \mathrm{~m} / \mathrm{s}$ slower condition $(p<0.05)$.

$80.32 \mathrm{BW} / \mathrm{s}$ based on our multiple regression equations (Figure 5). When running $5 \mathrm{~m} / \mathrm{s}$ at $0.43 \mathrm{BW}$, we predict that impact peak would be the same at $1.61 \mathrm{BW}$, active peak would decrease to $1.61 \mathrm{BW}$, and vertical loading rate would increase to $79.66 \mathrm{BW} / \mathrm{s}$ (Figure 5). Therefore, a person who normally runs $3 \mathrm{~m} / \mathrm{s}$ could run with an equal metabolic demand at $5 \mathrm{~m} / \mathrm{s}$ and $0.43 \mathrm{BW}$ in the G-trainer, have the same impact peak magnitude, decrease their active peak GRF by $\sim 32 \%$, but increase their vertical loading rate by $\sim 30 \%$.

\section{Discussion}

Methods other than lower-body positive pressure (LBPP) have been previously employed to support body weight during running, including harness systems and water immersion. Harness systems are beneficial scientifically because a purely vertical force can be applied to the runner and the resulting GRF and metabolic demand needed for supporting body weight alone can be independently addressed (Chang et al., 2000; Teunissen et al., 2007). However, harness systems may not be applicable for use over extended time periods because these systems can cause discomfort and impede circulation, and therefore may not be adequate training or rehabilitation devices. Coaches, athletes, and therapists have commonly used water immersion running as a training and rehabilitation tool. The metabolic power required for deep-water running can help to maintain aerobic fitness (Reilly et al., 2003). But deep-water running does not involve any GRFs, and kinematic patterns are quite different compared with over-ground running (Killgore, 2003; Moening et al., 1993). One of the advantages of a LBPP device is that running kinematics are much more similar to normal weight over-ground running than are water running kinematics; however, contact time and stride frequency do change slightly with body weight support during LBPP running (Table 2). In addition, LBPP devices such as the G-trainer are comfortable, do not impede circulation, can be used over extended time periods, and are adjustable; therefore, LBPP devices may be very effective training and rehabilitation tools.

The pressure-modulated lifting force of the G-trainer provided the desired vertical weight support, but also inadvertently provided horizontal assistance due to the interface between the chamber and the subject. On average, horizontal braking impulses were 18, 54, and 64\% greater than horizontal propulsive impulses for weight supported running at 3,4 , and $5 \mathrm{~m} / \mathrm{s}$, respectively. Assistive horizontal forces have no substantial effect on active peak vertical forces, decrease metabolic power demand, and greatly increase vertical impact peak forces and loading rates (Chang \& Kram, 1999; Chang et al., 2001). For example, Chang and Kram (1999) found that applying an assistive horizontal force of 3\% body weight resulted in horizontal braking impulses that were $56 \%$ greater 
than propulsive impulses during running at $3.3 \mathrm{~m} / \mathrm{s}$. This assistive force resulted in a $13 \%$ decrease in the rate of oxygen consumption and no change in the active peak vertical force compared with unassisted running. The results of Chang et al. (2001) suggest that an applied horizontal force of $3 \%$ body weight would increase impact peak force by $16 \%$ and increase vertical loading rate comparably.

Our results imply that the LBPP device applied horizontal assistance during the weight support trials. If no horizontal assistance was applied, impact peak, active peak, and vertical loading rate should have decreased between the 1.0 BW and $0.75 \mathrm{BW}$ trials and metabolic rate should have decreased moderately; however, we found that impact peaks and vertical loading rates were not significantly different for both $3 \mathrm{~m} / \mathrm{s}$ and $4 \mathrm{~m} / \mathrm{s}$, active peak forces decreased significantly, and metabolic power dropped sharply (Table 1). Runners did not run in the G-trainer during the $1.0 \mathrm{BW}$ trials and therefore were not subjected to any extraneous horizontal forces. Including the $1.0 \mathrm{BW}$ trials in our regression would imply that the G-trainer did not apply horizontal forces during the weight support trials; however, we found that the G-trainer did apply horizontal force. Therefore, we excluded the 1.0 BW data from the linear least-squares regressions for all variables except active peak, which is unaffected by applied horizontal force. Further, it may be beneficial to advise runners to position themselves in the middle of the G-trainer chamber aperture so that they can run with less horizontal assistance, thereby potentially minimizing their impact peaks and vertical loading rates while keeping a greater metabolic demand. It may also be useful to improve the design of the interface between the runner and the G-trainer so that horizontal forces can be minimized.

The G-trainer's positive air pressure provided a consistent and substantial lifting force to the subjects. We adjusted and set the air pressure in the chamber while subjects stood in place on the force treadmill before each weight support trial began. As subjects began to run, they settled into the neoprene short/spray skirt, which provided the interface between each subject and the G-trainer chamber. This slight shift in body position relative to the pressurized chamber caused a small change in the amount of weight support that we set before the trial. Because of this shift in position, average BW was not precisely fixed at $0.25,0.50$, and 0.75 for all conditions in the G-trainer (Table 1). We have accounted for and reported these slight differences in BW, and our overall results reflect this slight shift.

The G-trainer accommodates running with weight support at very fast, yet sustainable velocities. It is generally believed that training at high velocities can positively affect running performance by enhancing cardiovascular and neuromuscular function (Costill, 1979; Daniels, 2005). The ability to decrease the vertical active peak GRF may additionally benefit runners by reducing their potential risk for an overuse injury. Therefore, future studies are needed to address the long-term effects of training at high velocity and low weight in the G-trainer.

Lower-body positive pressure devices may be useful for rehabilitation because the amount of weight support and thereby the amount of active muscle force generation to support weight can be varied. Recovery from many types of injuries, such as ACL tears, stress fractures, and Achilles tendon ruptures, requires extensive rehabilitation that restricts the amount of weight and/or force that patients can support with their legs. Future studies are needed to determine appropriate velocities and weight support for recovery, and the potential reduction in recovery time offered by a weight support system such as the G-trainer. Because rehabilitation often starts with a walking prescription rather than running, additional studies are needed to determine the effects of velocity and weight support on ground reaction force production and metabolic power demand during walking.

In summary, velocity and weight support have separate and combined effects on GRFs and metabolic power demand during human running. By running at fast velocities with weight support, runners can reduce peak vertical GRFs while maintaining an aerobic stimulus. The G-trainer is a unique lower-body positive pressure device that may assist people in training and rehabilitation.

\section{Acknowledgments}

Alter-G, Inc. provided a G-trainer for this study and financial support for Alena Grabowski for the time period of the study.

\section{References}

Brockway, J.M. (1987). Derivation of formulae used to calculate energy expenditure in man. Human Nutrition. Clinical Nutrition, 41, 463-471.

Brooks, G.A., Fahey, T.D., \& Baldwin, K.M. (2004). Exercise physiology: Human bioenergetics and its applications. London: McGraw-Hill.

Cavanagh, P.R., \& Lafortune, M.A. (1980). Ground reaction forces in distance running. Journal of Biomechanics, 13, $397-406$

Chang, Y-H., Hamerski, C.M., \& Kram, R. (2001). Applied horizontal force increases impact loading in reduced-gravity running. Journal of Biomechanics, 34, 679-685.

Chang, Y-H., Huang, H.W., Hamerski, C.M., \& Kram, R. (2000). The independent effects of gravity and inertia on running mechanics. The Journal of Experimental Biology, 203(Pt 2), 229-238.

Chang, Y-H., \& Kram, R. (1999). Metabolic cost of generating horizontal forces in running. Journal of Applied Physiology, 86, 1657-1662.

Conley, D.L., \& Krahenbuhl, G.S. (1980). Running economy and distance running performance of highly trained athletes. Medicine and Science in Sports and Exercise, 12, $357-360$

Costill, D.L. (1979). A scientific approach to distance running. Mountain View, CA: Tafnews Press.

Costill, D.L., \& Fox, E.L. (1969). Energetics of marathon running. Medicine and Science in Sports and Exercise, $1,81-86$. 
Daniels, J. (2005). Daniels' Running Formula. Champaign, IL: Human Kinetics.

Daniels, J., \& Gilbert, J. (1979). Oxygen Power: Performance Tables for Distance Runners. Published by the authors. P.O. Box 5769, Flagstaff, AZ 86011-5769.

Farley, C.T., \& McMahon, T.A. (1992). Energetics of walking and running: insights from simulated reducedgravity experiments. Journal of Applied Physiology, 73, 2709-2712.

Ferber, R., Davis, I.M., Hamill, J., Pollard, C.D., \& McKeown, K.A. (2002). Kinetic variables in subjects with previous lower extremity stress fractures. Medicine and Science in Sports and Exercise, 34, S5.

Gerlach, K.E., White, S.C., Burtin, H.W., Dorn, J.M., Leddy, J.J., \& Horvath, P.J. (2005). Kinetic changes with fatigue and relationship to injury in female runners. Medicine and Science in Sports and Exercise, 37, 657-663.

Grimston, S.K., Nigg, B.M., Fisher, V., \& Ajemian, S.V. (1993). External loads throughout a 45 minute run in stress fracture and non-stress fracture runners. In Proceedings from the 14th. Paris: International Society of Biomechanics Congress.

Hamill, J., Bates, B.T., Knutzen, K.M., \& Sawhill, J.A. (1983). Variations in ground reaction force parameters at different running speeds. Human Movement Science, 2, 47-56.

Hamill, J., \& Knutzen, K.M. (1995). Biomechanical Basis of Human Movement. Williams and Wilkins.

He, J.P., Kram, R., \& McMahon, T.A. (1991). Mechanics of running under simulated low gravity. Journal of Applied Physiology, 71(3), 863-870.

Hreljac, A. (2004). Impact and overuse injuries in runners. Medicine and Science in Sports and Exercise, 36(5), 845-849.

Hreljac, A., Marshall, R.N., \& Hume, P.A. (2000). Evaluation of lower extremity overuse injury potential in runners. Medicine and Science in Sports and Exercise, 32(9), $1635-1641$.

Killgore, G.L. (2003). A biomechanical and physiological comparison of deep-water running styles. Unpublished Ph.D. thesis, University of Oregon, Eugene.

Kram, R., Griffin, T.M., Donelan, J.M., \& Chang, Y.H. (1998). A force-treadmill for measuring vertical and horizontal ground reaction forces. Journal of Applied Physiology, $85,764-769$.
Liu, W., \& Nigg, B.M. (2000). A mechanical model to determine the influence of masses and mass distribution on the impact force during running. Journal of Biomechanics, 33, 219-224.

Messier, S.P., Davis, S.E., Curl, W.W., Lowery, R.B., \& Pack, R.J. (1991). Etiologic factors associated with patellofemoral pain in runners. Medicine and Science in Sports and Exercise, 23, 1008-1015.

Moening, D., Scheidt, A., Shepardson, L., \& Davies, G.J. (1993). Biomechanical comparison of water running and treadmill running. Isokinetics and Exercise Science, 3, 207-215.

Munro, C.F., Miller, D.I., \& Fuglevand, A.J. (1987). Ground reaction forces in running: a reexamination. Journal of Biomechanics, 20, 147-155.

Nilsson, J., \& Thorstensson, A. (1989). Ground reaction forces at different speeds of human walking and running. Acta Physiologica Scandinavica, 136, 217-227.

Nilsson, J., Thorstensson, A.L.F., \& Halbertsma, J. (1985). Changes in leg movements and muscle-activity with speed of locomotion and mode of progression in humans. Acta Physiologica Scandinavica, 123, 457-475.

Reilly, T., Dowzer, C.N., \& Cable, N.T. (2003). The physiology of deep-water running. Journal of Sports Sciences, 21, 959-972.

Roberts, T.J., Kram, R., Weyand, P.G., \& Taylor, C.R. (1998). Energetics of bipedal running I. Metabolic cost of generating force. The Journal of Experimental Biology, 201, 2745-2751.

Teunissen, L.P.J., Grabowski, A.M., \& Kram, R. (2007). Effects of manipulating body weight and body mass on the metabolic cost of running. The Journal of Experimental Biology, 210, 4418-4427.

Weyand, P.G., Sternlight, D.B., Bellizzi, M.J., \& Wright, S. (2000). Faster top running speeds are achieved with greater ground forces not more rapid leg movements. Journal of Applied Physiology, 89, 1991-1999.

Whalen, R.T., Breit, G.A., \& Schwandt, D. (1994). Simulation of hypo- and hyper-gravity locomotion. In Proceedings from the American Society of Biomechanics Congress.

Zifchock, R.A., Davis, I., \& Hamill, J. (2006). Kinetic asymmetry in female runners with and without retrospective tibial stress fractures. Journal of Biomechanics, 39, 2792-2797. 